\title{
A ARTE E A RUA: UMA EXPERIÊNCIA COLABORATIVA AUDIOVISUAL COM ARTISTAS DE CIDADE TIRADENTES
}

\author{
ART AND THE STREET: A COLLABORATIVE AUDIOVISUAL EXPERIENCE \\ WITH ARTISTS FROM CIDADE TIRADENTES
}

*Carolina Caffé, **Rose Satiko Gitirana Hikiji

\section{RESUMO}

O artigo apresenta os primeiros resultados do projeto de extensão e da experiência de produção e exibição de um mapa digital interativo e de um filme etnográfico com artistas da Cidade Tiradentes, distrito periférico da Zona Leste da cidade de São Paulo. Discutimos a produção colaborativa do mapeamento, a realização do filme etnográfico e a circulação do filme, em especial, nos dois debates realizados em dezembro de 20 II com o apoio da Pró-Reitoria de Cultura e Extensão Universitária da Universidade de São Paulo. Os processos de produção do mapa e do filme, assim como os debates que sucedem seus lançamentos, apontam para a importância da produção compartilhada de conhecimento como metodologia dos trabalhos, para a potência criativa e política da apropriação popular das novas tecnologias, além de promover uma reflexão sobre a relação entre a produção artística e uma forma específica de apropriação do território urbano.

Palavras-chave: Gidade Tiradentes. Arte de rua. Filme etnográfico.

\begin{abstract}
The paper presents the first results of the project that proposes the extension of the experience of producing a digital interactive map and an ethnographic film with artists from Cidade Tiradentes, district in the outskirts of the city of São Paulo, East Zone. We discuss the collaborative production of mapping, the ethnographic film making, and the circulation of the film, especially in the two debates in December 2OII with support from the Office of the Provost of Culture and Extension, University of São Paulo. The production processes of the map and the film, as well as the discussions that follow their releases, point to the importance of shared knowledge as methodology of the work, for the political and creative power of popular appropriation of new technologies, and promote a reflection on the relationship between artistic production and a specific form of appropriation of the urban territory.
\end{abstract}

Key words: Gidade Tiradentes. Street art. Ethnographic film.

* É coordenadora executiva da área de comunicação e mídias livres do Instituto Pólis - Rua Araújo, I24, Centro - São Paulo SP - 01220-020 - e-mail: carol@polis.org.br. **Professora do Departamento de Antropologia da Faculdade de Filosofia, Letras e Ciências Humanas da Universidade de São Paulo (FFLCH-USP) - Av. Professor Luciano Gualberto, 3I5 - Cidade Universitária - São Paulo - SP - 05508-900 - e-mail: satiko@usp.br 


\section{INTRODUÇÃO}

$\mathrm{O}$ artigo apresenta os primeiros resultados do projeto A arte e a rua: extensão de uma experiência colaborativa audiovisual com artistas de Cidade Tiradentes, São Paulo, realizado pelas autoras, com apoio da Pró-Reitoria de Cultura e Extensão Universitária da Universidade de São Paulo, do Laboratório de Imagem e Som em Antropologia (LISA-USP) e do Instituto Pólis, por meio do projeto Pólis Digital $\dagger$. O projeto tem como objetivo estender as reflexões tecidas no processo de elaboração do Mapa das Artes de Gidade Tiradentes, concebido em 2009 pelo Instituto Pólis com apoio do Centro Cultural da Espanha, de São Paulo, e do filme etnográfico Aarte e a rua [I], realizado entre 2010 e $201 \mathrm{I}$, em coprodução do LISA-USP e do Instituto Pólis com apoio do Etnodoc II Edital de Apoio a Documentários Etnográficos sobre Patrimônio Imaterial (IPHAN).

O filme, dirigido pelas autoras deste artigo, aborda as transformações da arte de rua em Cidade Tiradentes, Zona Leste da cidade de São Paulo, e é um desdobramento do Mapa das Artes, um mapa interativo virtual $\ddagger$ que apresenta espaços culturais, artistas e suas produções, identificados e localizados de forma colaborativa entre os moradores da localidade, tendo como principal instrumento de pesquisa o audiovisual.

A partir da imersão no território e do contato com as obras e questões dos artistas de Cidade Tiradentes, formulamos a problemática central do filme, que buscamos desenvolver no presente projeto, em diálogo com os artistas e com o público das sessões de lançamento do filme: como a arte participa e dialoga com os processos de transformação do território? Outras temáticas, elencadas desde a produção do mapeamento, foram retomadas nos debates promovidos para o lançamento do filme, e serão detalhadas aqui, tais como: o filme como meio de se aproximar de um território; o filme como linguagem e a figura do morador como narrador; as relações entre a arte e o território e entre arte e política.

Além da reflexão sobre os temas colocados em pauta pelos próprios artistas de Gidade Tiradentes, o

$\dagger$ Este projeto é Ponto de Mídia Livre, prêmio do Ministério da Cultura, uma ação de desenvolvimento e acompanhamento de construção de políticas públicas para iniciativas de comunicação livre e compartilhada.

$\ddagger$ Ver em <www.cidadetiradentes.org.br>. presente projeto pretende sistematizar as metodologias utilizadas, desde a produção colaborativa do mapeamento até a experiência da produção fílmica e as surpresas nos processos de gravação e montagem. Questões a respeito do uso do vídeo como ferramenta de pesquisa e forma específica de produção e divulgação de conhecimento, da antropologia compartilhada, das formas visuais e virtuais de difusão de conhecimento são alguns dos temas que propomos desenvolver.

Neste artigo, apresentamos as reflexões que serão, como parte deste projeto, apresentadas em livreto que contará com textos, fotos e um DVD com o filme $A$ arte e a rua, além de materiais audiovisuais produzidos no processo de pesquisa e exibição dos filmes, como a edição dos debates de lançamento. Este livreto está em fase de produção e deve ser finalizado e distribuído ainda em 2012.

\section{CIDADE TIRADENTES EM MAPA E FILME: MATERIAIS E MÉTODOS}

A Cidade Tiradentes, distrito que possui o maior conjunto habitacional popular da América Latina, foi construída há cerca de 30 anos como bairro dormitório, fruto de um planejamento estatal para deslocamento de populações atingidas por obras públicas. Dista mais de $35 \mathrm{~km}$ do Centro, localizando-se no ponto extremo da Zona Leste da cidade de São Paulo, a capital paulista. Possui hoje mais de 50 mil unidades habitacionais, com cerca de quase 220 mil pessoas ${ }^{\S}$. É "onde a cidade começa", segundo o subprefeito Renato Barreto, ou "onde a cidade termina", na opinião de Daniel Hylário, ativista cultural morador do distrito".

O Mapa das Artes de Cidade Tiradentes, produzido em 2009, apresentou as informações da comunidade por meio de vídeos, fotos, músicas e textos, utilizando-se da tecnologia Mashup, que cruza plataformas virtuais, como Google Maps, YouTube e Flickr, para criar um novo serviço personalizado. Organizado sobre um mapa físico e geográfico do distrito, nele é possível

§ Dados da subprefeitura da Cidade Tiradentes, disponíveis em $<$ http://www.prefeitura.sp.gov.br/cidade/secretarias/subprefeituras/cidade_tiradentes/historico/index.php?p=94>. Acesso em: I4 maio 2012.

It Daniel e Renato são alguns dos protagonistas do filme Arte e a rua. Renato Barreto era o subprefeito de Cidade Tiradentes na época das filmagens (2010). 
localizar pessoas, grupos, espaços e eventos relacionados às linguagens da Música, Dança, Audiovisual, Artes Plásticas, Literatura e Teatro.

O Mapa das Artes é o resultado do projeto Cartovideografia Sociocultural da Cidade Tiradentes ${ }^{* *}$, que teve como objetivo contribuir para o fortalecimento da cidadania cultural dos moradores; revelar e potenciar os saberes, fazeres e poéticas culturais do bairro pela ampliação da visão dos próprios agentes locais sobre suas práticas; favorecer o conhecimento e a valorização dos espaços pelos seus habitantes, incidindo também na representação que pessoas de outros bairros têm sobre a Gidade Tiradentes; e favorecer a interlocução entre diferentes grupos e dinâmicas locais para criação de espaços comuns e potencialização de redes ${ }^{\dagger \dagger}$.

$\mathrm{O}$ projeto da cartovideografia procurou explorar "tanto os aspectos topográficos quanto biográficos que nos falam das problemáticas de diferentes grupos. Assim, além do reconhecimento do território físico, e a sua nomenclatura local, ela buscou os territórios subjetivos, afetivos, existenciais, constituídos pela experiência cotidiana”

Para dar conta de tal objetivo, o projeto previa o "envolvimento de atores locais visando à construção do produto final de forma participativa”. Este aspecto participativo foi determinante para a concepção metodológica posterior do filme etnográfico.

A equipe do projeto foi composta por pesquisadores do Instituto Pólis, consultoras etnográfica e audiovisual, e quatro moradores de Cidade Tiradentes que, no bairro, desenvolvem atividades em diversas linguagens artísticas. As autoras deste artigo compunham esta equipe $\$$.

Com estes pesquisadores-moradores, construímos questões e problemas que foram a base do roteiro de entrevista que iriam compor o Mapa das Artes de Gidade

\footnotetext{
** Uma apresentação audiovisual do projeto pode ser vista em 〈http://youtu.be/B77LpJQIWEo>.

$\dagger \dagger$ Apresentação do projeto Cartovideografia Sociocultural da Cidade Tiradentes, ver em <www.cidadetiradentes.org.br>.

$¥$ † Texto do projeto Cartovideografia Sociocultural da Cidade Tiradentes, elaborado pela área de Desenvolvimento Cultural do Instituto Pólis (2009).

§ Carolina Caffé, Hamilton Faria e Luis Eduardo Tavares compunham a equipe de coordenação do projeto pelo Instituto Pólis. Rose Satiko foi a consultora etnográfica; Eliane Caffé participou da fase inicial como consultora audiovisual; Daniel Hylário, Bob Jay, Cláudia Canto e Cláudio Tio-Pac foram os pesquisadores-moradores.
}

Tiradentes. Com uma câmera de vídeo em mãos e este roteiro, os pesquisadores registraram mais de 50 entrevistas, editadas posteriormente pelo Núcleo de Comunicação Artística (NCA) IIII, coletivo de realização de vídeos da periferia da Zona Sul da cidade de São Paulo****.

\section{ANTROPOLOGIA COMPARTILHADA: DO MAPA AO FILME ETNOGRÁFICO}

A opção pelo uso do audiovisual como ferramenta da cartovideografia, associado à metodologia participativa, faz necessária a referência ao trabalho pioneiro do antropólogo-cineasta Jean Rouch. Este autor, que tem inspirado diversos trabalhos em antropologia visual, percebeu - já na década de 1950 - o cinema como uma forma de produzir conhecimento com os africanos com os quais realizava suas pesquisas. Os filmes - diferentemente das teses acadêmicas - seriam vistos e discutidos por seus interlocutores. Nos filmes, a coautoria foi experimentada de forma radical por Rouch e seus amigos africanos [8].

A antropologia compartilhada foi experimentada nesta pesquisa de diversas maneiras: na colaboração intensa com os artistas moradores de Cidade Tiradentes, convidados a atuar como pesquisadores na equipe do mapeamento; no uso do audiovisual como ferramenta para a realização das entrevistas e gravações com 50 dos 200 grupos mapeados; no produto da pesquisa, um website interativo, fruto do objetivo de que o conhecimento produzido na e com a comunidade fosse efetivamente apropriado por ela.

Enquanto produzíamos o Mapa das Artes de Cidade Tiradentes, percebemos a riqueza do contexto em que adentrávamos e delineamos um projeto de filme etnográfico a partir daquela pesquisa. Inscrevemos este projeto no Etnodoc II - Edital de Apoio a Documentários Etnográficos sobre Patrimônio Imaterial (IPHAN), e fomos um dos 16 projetos selecionados em todo o país para realização de um filme de 26 minutos que foi exibido na TV Brasil e em festivais nacionais.

O projeto, intitulado A arte e a rua, previa a abordagem das transformações da arte de rua em Cidade

\footnotetext{
II Ver em <http://ncanarede.blogspot.com>.

*** O resultado pode ser conferido nos vídeos editados pelo coletivo, postados no sítio 〈www.cidadetiradentes.org.br〉.
} 
Tiradentes. Selecionamos quatro dos 200 grupos mapeados como "personagens" de nosso filme, que tinha como questão mais geral o diálogo entre os artistas e os processos de transformação do território.

A versão mais curta do filme, intitulada Lá do leste [4], foi exibida em julho de 20II na TV Brasil. Acompanha a experiência de quatro grupos ligados ao Hip Hop, que cresceram junto com a Cidade Tiradentes, e, em suas obras, dialogam com seus desafios e sonhos: grupo de grafite 5 Zonas; grupo de rap RDM - Rapaziada Do Morro; grupo de dança Tiradentes Street Dancers e grupo de rap gospel Relato Final. A arte e a rua é a versão final do filme, um média-metragem que incorpora, além da apresentação dos grupos, as reflexões de Daniel Hylário sobre as transformações no bairro e a arte em Cidade Tiradentes.

O diálogo dos artistas de rua com as transformações do território, advindas do processo de urbanização da periferia, foi a questão central que orientou a produção fílmica e que se formou no processo do mapeamento. Os quatro pesquisadores-moradores convidados a participar da elaboração e produção do mapa virtual são artistas que nasceram ou cresceram na periferia de São Paulo na década de I980. Estão vinculados com o movimento Hip Hop e foram escolhidos para o projeto pelo reconhecimento de suas trajetórias políticas na região e por seu pensamento crítico sobre as disputas culturais locais.

Apesar de hoje ser o funk a linguagem musical hegemônica na comunidade, o Mapa das Artes apresentou majoritariamente vertentes da arte de rua e do movimento Hip Hop. Isto se deu em função da "rede de contatos" e de conhecimento dos pesquisadores envolvidos no projeto - mais próximos da geração artística nascida nos anos I980 que da juventude propriamente dita - ou mesmo de artistas mais velhos. Resultado deste "recorte" não planejado pelo projeto foi a constatação de uma história do distrito, da transformação do território e dos grupos ligados à arte de rua. É o olhar destes artistas e moradores, profundamente marcados pelo Hip Hop e pela vivência nesta periferia urbana, que buscamos apresentar nos filmes etnográficos A arte e a rua e Lá do leste.

Três formas narrativas são entrelaçadas na confecção dos filmes. A primeira é a apresentação do que chamamos de etnografia dos grupos: uma descrição de seus deslocamentos no território, os equipamentos e espaços que utilizam para apresentações e ensaios, suas práticas artísticas, sua sociabilidade e suas reflexões. Para dar conta desta narrativa, experimentamos técnicas do cinema de observação e do participativo, em registros das ações cotidianas, das performances e de depoimentos e conversas informais $[2,3,5,6,7]$.

A segunda narrativa explora a metodologia da "câmera-bastão". No filme, propusemos a alguns dos nossos personagens que levassem a câmera providenciada pela produção para registrar elementos de seu cotidiano: poderiam gravar seu trabalho, o distrito, os preparativos para as apresentações, além de filmar livremente o que achassem interessante. No filme, Daniel Hylário, Bob Jay e Michelle Fleury - a esposa de Denilson, o rapper evangélico - empunharam a câmera para gravar o seu universo sem a presença da equipe. Os resultados foram tão surpreendentes que formam parte significativa do corte final do filme.

A terceira narrativa do filme é a que chamamos de "experimental". Foram coproduções em que equipe e atores sociais realizaram audiovisuais que expressam suas formas artísticas em uma linguagem mais livre. Esta linguagem foi experimentada principalmente no stop motion com o grupo de grafite 5Zonas, dirigido por Andre Farkas e Arthur Guttilla e em um videoclipe com o grupo $\mathrm{RDM} \dagger \dagger \dagger$, dirigido por nós e editado por Ricardo Berro.

\section{EXIBIÇÕES E DEBATES: PRIMEIROS RESULTADOS}

A exibição para o público é o momento de concretização da experiência de produção do filme. Ali, o espectador completa o sentido da obra com a sua opinião, sua ênfase, seu olhar sobre o que é apresentado. Neste sentido, podemos dizer que não existe uma visão original e mais verdadeira que outra sobre uma obra. Nem a do roteirista ou diretor. A obra, quando está no ar, já não pertence mais ao produtor. Ela é agora do mundo e passível a reinterpretações, refutações e ressignificações.

$\mathrm{Na}$ expectativa por esta diversidade de reapropriações da obra, organizamos dois encontros de exibição e debate do documentário A arte e a rua, sendo um no centro da cidade de São Paulo (Matilha Cultural)

$\dagger \dagger \dagger$ Ver em 〈http://vimeo.com/lisausp/barro-branco-rdm〉. 
e outro na periferia (Instituto Pombas Urbanas, em Cidade Tiradentes). Convidamos para o debate representantes do setor público, do terceiro setor, acadêmicos, produtores culturais, artistas locais e protagonistas do filme para garantir a pluralidade de olhares sobre a obra, imaginando também que tal encontro resultaria em uma série de tensões entre os diferentes pontos de vista, que ansiávamos conhecer.

\section{O FILME COMO APROXIMAÇÃO DE UM TERRITÓRIO}

Ao abrir a mesa de debate da sessão que aconteceu no cineclube Matilha Cultural, Hamilton Faria, poeta e diretor do Instituto Pólis, apresentou ao público a metodologia da "Ausculta Sociocultural", desenvolvida em projetos de mapeamento realizados pelo instituto e que resultaram tanto em sítios quanto em publicações. Esta metodologia, que "ouve os ruídos interiores, as subjetividades, a vida, e não apenas o que se pensa objetivamente sobre o bairro ou o que está expresso em uma manifestação artística”, utilizada na confecção do Mapa das Artes de Gidade Tiradentes, teria reflexo direto no documentário $A$ arte e a rua. Foi a partir da atenção aos ruídos e subjetividades da vida em Cidade Tiradentes que pensamos o filme, sendo que sua realização foi também outro momento privilegiado de ausculta.

Destacando o formato fragmentário do filme, Henri Gervaiseau, cineasta e professor da Escola de Comunicações e Artes da Universidade de São Paulo (ECA-USP), caracteriza a obra como sendo "uma aproximação muito delicada do cotidiano do lugar, e ao mesmo tempo um pouco do comentário do cotidiano". Tal aproximação se daria por meio de Daniel Hylário, personagem central que ocupa o lugar de narrador no filme, que nos "ajuda a realizar o percurso pelo território", mas também "pela própria arte de rua que nos é mostrada”, que opera como comentário da vida.

Gil Marçal também compôs a mesa de debate sobre o filme. Gil é coordenador do Programa para a Valorização de Iniciativas Culturais (VAI), criado por meio de dispositivo de lei e que tem como finalidade o apoio a atividades artístico-culturais, principalmente de jovens de baixa renda e de regiões do município paulistano desprovidas de recursos e equipamentos culturais. $\mathrm{Ou}$, em suas palavras, "uma ação que pretende quebrar o estigma de que não há arte e cultura na periferia”.
O aspecto compartilhado da narrativa no filme - e que, às vezes, gera a sensação de "filme fragmentado" ganha destaque na fala de Gil:

Este filme dialoga muito com o olhar desses grupos jovens que produzem o audiovisual, o vídeo na periferia. E aí, talvez, uma importância extrema que eu acho que esses grupos têm e que esse vídeo dialoga de uma forma muito interessante, é de fazer a sua própria mídia. É de abrir esse espaço pra comunicar. Sair do grande circuito das doze famílias que dominam a comunicação do país e falar, com o advento do preço mais barato dos equipamentos, com acesso à internet, em ser um sujeito comunicador.

\section{O FILME COMO LINGUAGEM: DANIEL, O NARRADOR}

Em Gidade Tiradentes, o debate teve lugar no Centro Cultural Arte em Construção (Instituto Pombas Urbanas). Ao abrir o debate, a antropóloga e professora da Escola de Comunicações e Artes da USP (ECA-USP), Esther Hamburger - que desenvolveu projeções de cinema para a comunidade do distrito, em projeto no qual conheceu Daniel Hylário, dentre outros moradores - chamou atenção justamente para os enquadramentos buscados por nosso protagonista quando a câmera estava em suas mãos. No filme, Daniel dirigiu a realização do que chamamos "câmera-bastão”, tendo sido, ele próprio, o realizador de parte importante das imagens produzidas com a handycam pelos moradores-artistas. Esther lembrou-se de discussões que travou com Daniel sobre a questão dos enquadramentos: "Como é que se enquadra, como é que o enquadramento pode estar simplesmente contribuindo pra reproduzir um estereótipo, ou pra dissolver estereótipos e mostrar coisas em ângulos novos". E, mencionando uma sequência que foi filmada no Barro Branco - um dos "setores" de Cidade Tiradentes, que reconheceu em função de uma escada -, Esther perguntou sobre as opções formais, que, em sua opinião, fazem com que o filme seja diferente de outros.

Daniel destacou que as locações utilizadas tanto na gravação do videoclipe da música Barro Branco (que integra o filme A arte e a rua) como no documentário foram estudadas para facilitar o reconhecimento do bairro: 
Porque a Tiradentes é enorme, mas se você focar um ponto que todos conhecem, vão identificar rapidamente que é a Tiradentes. O Barro Branco, nós colocamos aquele escadão ali, porque a comunidade conhece aquele escadão. Locais onde a comunidade circula e conhece. E também dar outra visão pra quem vem de fora.

Desde o processo de pesquisa para o documentário, tínhamos percebido a importância que Daniel atribuía à apresentação do território. A cena final do filme é gravada em um dos primeiros locais aos quais Daniel nos levou quando pedimos que ele nos apresentasse a localidade. "Aqui é o fim de Cidade Tiradentes", em suas palavras reproduzidas no filme. Mas aquele local, nas bordas do distrito, tomado ainda por Mata Atlântica, do qual avistamos boa parte da região, é também um espaço aberto à imaginação. "Como será Cidade Tiradentes daqui a dez anos?", pergunta Daniel aos seus interlocutores, exatamente neste pedaço de terra ainda não habitado.

No debate no Matilha Cultural, Heitor sintetizou da seguinte maneira sua percepção de Cidade Tiradentes por meio de Daniel, nosso narrador:

$\mathrm{Na}$ variedade de perspectivas, o personagem Daniel parece sintetizar apreensões que atravessam tais falas, com um cabedal significativo de conceitos (sociabilidade, igualdade, individualidade, prosperidade etc.) que, por fim, ganham um alto teor de utopia ao imaginar como seria "colorir toda a dor", enquanto caminha por espaços recortados apenas por picadas, que simbolizariam uma fronteira de urbanização, mas também um espaço de um possível reinício, marcado por novos códigos, mais humanos, de relações, onde todos estariam juntos [novamente] por livre escolha.

\section{A ARTE E A RUA}

"Talvez a rua seja o grande lugar, como diria Mia Couto, lugarizado, onde a arte acontece fora dos templos da cultura", afirmou Hamilton na abertura do evento, destacando o caráter público e privado dos espaços culturais, institucionalizados e não institucionalizados. Para Hamilton, a relação entre a Arte e o território é dialética. Pela Arte acessamos o território.
Mas a Arte igualmente o produz, "vai redesenhando a cidade, vai reencantando a cidade, vai potencializando novos atores, vai construindo uma estética [...] apoiada na simplicidade, nas cores, na vida urbana ressignificada".

No Pombas Urbanas, o sociólogo Tião Carvalho levantou uma importante inquietação: se o filme propõe pensar a rua como espaço de troca, de saberes, e de sociabilidade, como a Arte pode dialogar com este espaço público?

Sinto falta do diálogo efetivo da arte com os espaços públicos, para desenvolver uma reflexão sobre a sociabilidade do trajeto, da mobilidade daqui, do traçado urbano, desde a própria arquitetura dos prédios às novas arquiteturas da construção dos muros.

Para responder à provocação, Everaldo Matias, o Ever4 do coletivo de grafite 5 Zonas, trouxe um pouco do que conhece da história do distrito.

Quando eu chequei aqui, em 2005, eu vi um bairro em que faltava muita coisa. Eu moro em Guaianazes, não é muito longe daqui, e também não é uma realidade muito diferente daqui. E desses seis, sete anos pra cá, eu vi muita coisa mudando, muita coisa aparecendo aqui, como os próprios prédios públicos, o CEU vindo pra cá, hospital vindo pra cá, agência bancária, posto de gasolina e tal. Então, nesses sete anos eu vi bastante coisa que o 5 Zonas não consegue falar nos murais que a gente pinta frequentemente aqui, e um vídeo realmente ia ser bem difícil contar em alguns minutos.

Mas Everaldo diz que o coletivo "também questiona muitas outras coisas". Exemplifica com o primeiro mural que fizeram em Tiradentes, no qual "a gente questionou e mostrou a história que a gente identificou, de pessoas que ouviram falar dos avós, da época em que aqui tinha escravos e tudo mais, e no mesmo mural a gente mostrou sonhos, como fábricas, um emprego...”.

O antropólogo Heitor Frúgoli, que compôs as mesas de debates no Matilha Cultural e no Instituto Pombas Urbanas, identifica em todos os grupos artísticos apresentados o reconhecimento de novos espaços conquistados e novos status da arte de rua, 
acompanhado do sentimento de perda da "união por uma causa comum”, e da própria rua.

Por exemplo, quando o [street dancer] Ivan fala: "Nós estamos agora conseguindo espaço nas escolas, nos CEUs, nas ONGs etc. e tal. Mas há uma perda também, já não existe mais a mesma força que tinha como quando ele [o street dance] acontecia na rua". O grafite também aparece com uma inquietação um pouco parecida: ele vai ganhando reconhecimento institucional, começa a ganhar os museus, as galerias, e tudo o mais. Ao mesmo tempo aparece uma ideia de que tem uma força que está na rua, que precisa ser resgatada lá de trás. Mas às vezes a rua, ou o passado, vai ganhando quase que um caráter meio mítico. Bom, todo mundo tava junto, agora tá todo mundo mais separado.

No debate em Pombas Urbanas, Heitor lançou para os artistas de Cidade Tiradentes o questionamento: "Vocês concordam com essa ideia que está no filme, que cada conquista traz novos problemas também? Traz novos desafios? Quer dizer, a gente conquista espaços, conquista reconhecimento, mas parece que perde alguma coisa política que precisa ser resgatada lá de trás?".

Dentre as várias respostas, destacamos a do rapper Bob Jay, do grupo RDM, um dos protagonistas do filme:

A gente fala muito do nosso passado, como era aqui, e parece que a gente não tá conformado com o que está aqui hoje. [...] Mas... Aquilo lá era melhor? Porque nós perdemos nossas raízes, nossas origens, na verdade, né? O Hip Hop veio da rua e não está mais na rua. $\mathrm{O}$ grafite veio da rua e também não está mais na rua. Os que estão na rua são os rebeldes, os que falam "não, eu sou da rua, na rua eu fico!" É os rapper que tão na rua. RDM luta há I6 anos no movimento Hip Hop e organiza, frente a frente com a favela lá, o "a favela é nossa". E é nóis por nóis! Tá entendendo? Não tem apoio de ninguém, e eu sinto falta dessa essência. Quando eu vim aqui pro 65, vi a Aliança Negra organizando o movimento do Hip Hop, o bagulho era um fervor danado, achava da hora. Você ficava quatro, cinco horas aqui esperando pra cantar um som só. E saía satisfeito. O Força Ativa, a mesma coisa. Hoje você vai num lugar pra cantar, se cantar um som você sai revoltado! Você que ir lá cantar duas horas, três horas, e acha que não tá bom! E conforme as coisas vão vindo, a gente vai evoluindo, a gente também tem uns não, né! Tem um CEU, tem uns espaços públicos, você quer utilizar também, mas é o lado burocrático que te limita chegar àquele acesso. E você tem que ser do jeito que eles põem pra você, não é do jeito que você aprendeu. Tá ligado? E acho que isso aí atrapalha um pouco, você perde a essência, né mano? Nós perdemos a essência. $\mathrm{E}$ quando um vai, não leva todos. $\mathrm{E}$ os todos tão aqui. É mais ou menos isso aí.

O rapper Douglas, da Família RDM, colocou-se após a fala de Bob Jay. Morador de Tiradentes desde I990, o rapper concorda que as mudanças no distrito têm relação com as transformações na arte de rua:

Antigamente, o bairro era rua de barro, nós esperávamos meia noite pra sair água de um cano, e aquela fila enorme de gente com balde. Aí o rap retratava aquilo. Todo mundo gostava de ouvir porque era um protesto, todo mundo se unia pra protestar contra aquilo. Por uma rua asfaltada... Conforme nós fomos conseguindo isso, as pessoas foram se dividindo.

Everaldo, do 5Zonas, pede a palavra para dizer que acha "natural, o lance da conquista acabar tirando você um pouco do coletivo":

E eu acho que cabe a cada um diagnosticar se isso é positivo pra ele ou não, porque prós e contras tem, né? Beleza, você vai ter que se ausentar um pouco do coletivo pra você poder sustentar sua casa? Legal, você tem que colocar um pouco na balança. Acontece, mas eu acho que caso a caso cada um tem que diagnosticar o que é melhor pro momento e pro movimento que segue.

Paniquinho, que acompanhava o debate na plateia, pede a palavra para narrar seu conhecimento com relação ao Hip Hop, uma vez que se reconhece como participante de uma das primeiras gerações do movimento. Em 1994, participou da primeira posse de Hip 
Hop de Tiradentes, a Aliança Negra. Seu relato dialoga com questões apontadas pelo filme e trazidas para o debate pelos participantes:

A Cidade Tiradentes era mesmo um projeto arquitetônico de cidade dormitório. Foi colocada aqui, não tinha políticas públicas mesmo, não tinha nada, e uma das nossas necessidades enquanto jovens era, na apropriação do espaço, se manifestar culturalmente. [...] Então foi através do Hip Hop que a gente começou a se apropriar e desenvolver algumas ações, que poderiam se chamar de ações sociais, porque na época não existia ONG, não existiam ações [...]. Tinham algumas lideranças do bairro, alguns militantes do movimento negro, algumas pessoas que vieram pra cá e que já eram lideranças populares da onde vieram, e que começaram ... E nós, enquanto jovens, desenvolvendo esse diálogo a partir da cultura.

Houve um momento em que o Hip Hop, se manifestando nesse bairro, era um público maior do que aquele do funk que aparece no vídeo! Porque era uma das únicas manifestações que tinha.

[...] Teve um momento em que a gente se organizava pra fazer um evento que era pra arrecadar alimento e agasalho pras famílias que eram mais necessitadas no bairro. Se não há mais essa necessidade, qual que é a nossa próxima reivindicação?

[...] O que a gente quer enquanto artista? Vou fazer essa provocação... Pro grafite é muro pra pintar? É material? Pro MC, é um microfone, é palco? "Ah... eu não tenho mais motivação pra escrever sobre tal coisa que não existe mais porque não tem mais chão de terra, então não vou mais escrever?" O que move a minha motivação pra que eu possa continuar sendo considerado um artista que interfere na mudança da realidade? Ou não? Ou é dinheiro? Será que é dinheiro? Será que é... Pode ser dinheiro, e pode mudar? Porque a impressão que dá também é que quando se fala que o Hip Hop não tá no mesmo patamar que um funk, ou que não sei o que, é como se o Hip Hop não conseguiu atingir alguns objetivos... Eu consegui atingir alguns dos meus objetivos com o
Hip Hop, sendo mediador disso. Hoje eu sou formado numa universidade, hoje eu tenho minha família, hoje eu tenho alguns bens materiais, e eu entendo que o Hip Hop foi o mediador disso, então se eu acreditar que o Hip Hop não contribuiu com isso, vou achar que o Hip Hop foi sempre um fracasso na minha vida e vai ser sempre um fracasso, e não é!

\section{TRANSFORMAÇÕES NO TERRITÓRIO}

Henri Gervaiseau chamou atenção para as perguntas levantadas no final do filme - no diálogo entre os personagens - sobre o destino do território: "Daqui a dez anos, como é que vai ser [Cidade Tiradentes]? Vai ser um Morumbi, vai ser o [bairro dos] Jardins? Talvez não seja nem uma coisa nem outra, talvez seja ainda outra coisa". Para Henri, São Paulo "é sempre de alguma maneira o novo mundo, no sentido que não é uma cidade dada, pela maneira como ela acabou existindo". Henri fala sobre periferia, mas também fala sobre a ausência de qualidade do planejamento urbano na cidade.

Heitor Frúgoli lembrou que Gidade Tiradentes representa uma área com problemas urbanos decorrentes não da ausência do Estado, mas da presença deste no âmbito local, "já que se trata de um enorme conglomerado de habitações sociais agenciadas pelo poder público que, entretanto, não dotou tal espaço de uma urbanização mais consistente". Heitor destaca que o documentário permite captar certas combinações entre mudanças e permanências desse contexto urbano:

Costuma-se dizer que na periferia as novas gerações estabeleceram certas rupturas com as anteriores quanto às inserções profissionais, à relação com a violência e a criminalidade, aos gostos e estilos musicais, às formas de sociabilidade e de consumo. Entretanto, é preciso atentar para certas falas ditas pelos personagens desse filme, que talvez ajudem a complexificar esse quadro. Daniel Hylário, espécie de 'fio condutor' de todo o filme, lembra que "antes o encontro entre as pessoas era maior", "os prédios da COHAB não tinham muros", "nos mutirões as pessoas estavam mais compactas". Mas lembra que isso teria sido muito definido pela necessidade, pela premência, pela carência material. 
Daniel Hylário comenta a leitura dos debatedores:

Às vezes a gente não se vê como ser histórico, a gente não sabe que tá fazendo história, e de repente uma atitude nossa influencia outras pessoas e, automaticamente gera outras consequências. E foi isso com o Hip Hop, foi isso com os jovens que eu conheço. Então de repente alguma coisa muda, a sua atitude muda, e automaticamente isso influencia várias pessoas a mudarem e a tomar a mesma postura.

\section{ARTE E POLÍTICA}

"De que modo vocês pensam, dentro dos seus grupos, que este documentário pode ser distribuído, veiculado no bairro, onde as pessoas possam se reconhecer. Reconhecer não somente enquanto linguagem, mas enquanto debate político?” A questão de Tião Carvalho é central e algumas respostas foram esboçadas já no debate.

Um ponto bastante questionado pelos presentes foi a relação do poder público com a arte em Cidade Tiradentes. No filme, o então subprefeito, Renato Barreiros, justifica o apoio que oferece ao funk, pelo fato desta linguagem "arrastar multidões", diferentemente do rap ou de outros estilos.

Para Henri Gervaiseau, é "um discurso absolutamente lamentável desse cidadão brasileiro que acha que o mercado é o que o Estado deve abraçar". "A Arte tá na rua e tem que ter público, se a Arte tá na rua e não tem público, não é Arte?”, pergunta Daniel. O street dancer Ivan expressa sua indignação: "Infelizmente a fala do Renato [subprefeito] me machucou muito, desculpa, machucou muito mesmo, ele fala que o Hip Hop é politizado, e não é isso que ele quer, ele quer a festa que chama mais atenção. Desculpa, não dá pra entender, não dá! Não dá pra engolir isso, não dá mesmo!”.

\section{COMPARTILHAR O CONHECIMENTO: PROVOCAÇÕES}

Em uma provocação, Paniquinho, que acompanhava o debate na plateia, questiona a produção de conhecimento sobre a periferia a partir do Centro, e atenta para a centralidade de Daniel no filme:
Eu não gosto muito dessa palavra, "objeto de estudo"... Eu sou atuante dessa história. Eu olho o vídeo e fico pensando como seria esse vídeo sem a fala do Daniel no decorrer do vídeo todo... narrando isso tudo, e amarrando todas as falas de todo mundo. Talvez a maior teoria, o maior teórico dentro do espaço universitário, talvez não conseguisse traduzir de forma tão interessante o que ele traz. Mas por quê? Porque ele tem a vivência, ele tem o conhecimento, conhece o bairro, conseguiu entender essa transformação.

Ivan, do Tiradentes Street Dancers, também questiona o exercício investigativo fílmico. "Você enxerga a pessoa como um ser estudado, né? Você estuda aquilo pra entender, né? Meu, vive lá que você vai entender! É fácil você falar porque você tá aqui, na sua zona de conforto, vai pra lá pra você ver como é que é".

Em ambos os debates, como em todo o exercício de aproximação para a pesquisa, elaboramos nosso projeto de conhecimento, que se afasta bastante daquele que toma como "objetos de estudo" os sujeitos com quem se produz saberes. Desde o mapeamento, a possibilidade de produção compartilhada de conhecimento foi um pressuposto de nossas pesquisas.

No debate na Matilha Cultural, tentamos responder à inquietação do Ivan, afirmando a impossibilidade de nós, pesquisadores, um dia "sermos de Cidade Tiradentes":

A gente tenta se aproximar por meio de vocês, do que vocês nos apresentam como Cidade Tiradentes. Reconhecemos que a experiência de ser de Tiradentes é exclusiva de vocês, mas vocês nos apresentam essa experiência de formas densas, por meio da arte de vocês, por meio da fala, das reflexões, os problemas que a gente ouve e compartilha.

Mas ouvindo novamente todas as falas, dos protagonistas do filme, dos participantes e do público no debate, fica mais claro o potencial do filme em apresentar estes sujeitos a partir de suas próprias perspectivas. As leituras de nossos interlocutores revelam que são vários os caminhos reflexivos e sensíveis que cada protagonista do filme propõe. Daniel, Ivan, os rappers do RDM, cada membro do 5 Zonas e do Relato Final são os autores deste mosaico que apenas ajudamos a compor. 


\section{REFERÊNCIAS BIBLIOGRÁFICAS}

[I] A ARTE E A RUA. Direção de Carolina Caffé e Rose Satiko Hikiji. São Paulo: LISA/Pólis, 20II. HDV ( 46 min), color. Trailer do filme disponível em <http:// vimeo.com/lisausp/aarteearuatrailer $>$.

[2] BARNOUW, Erik. Observer. In: Documentary: a history of the non-fiction film. Oxford/New York: Oxford University Press, 1993. $400 \mathrm{p}$.

[3] DA-RIN, Silvio. Espelho partido: tradição e transformação do documentário. Rio de Janeiro: Azougue Editorial, 2004. $248 \mathrm{p}$.

[4] LÁ DO LESTE. Direção de Garolina Gaffé e Rose Satiko Hikiji. São Paulo: MoviArt/LISA/Pólis/WS, 20IO. HDV (26 min), color. Filme disponível na íntegra em $\langle$ http://vimeo.com/lisausp/ladoleste $>$.

[5] MACDOUGALL, David. Beyond observational cinema. In: HOCKINGS, Paul. Principles of Visual Anthropology. Berlin: Mouton de Gruyter, 1995. $562 \mathrm{p}$.

[6] Transcultural Ginema. Princeton: Princeton University Press, 1998. 528 p.

[7] NICHOLS, Bill. Introdução ao documentário. Campinas: Papirus, 2005. $270 \mathrm{p}$.

[8] PIAULT, Henri. Anthopologie et cinema. Paris: $\mathrm{Na}-$ than, 2000. $285 \mathrm{p}$. 


\section{ANEXO}

IMAGEM 1

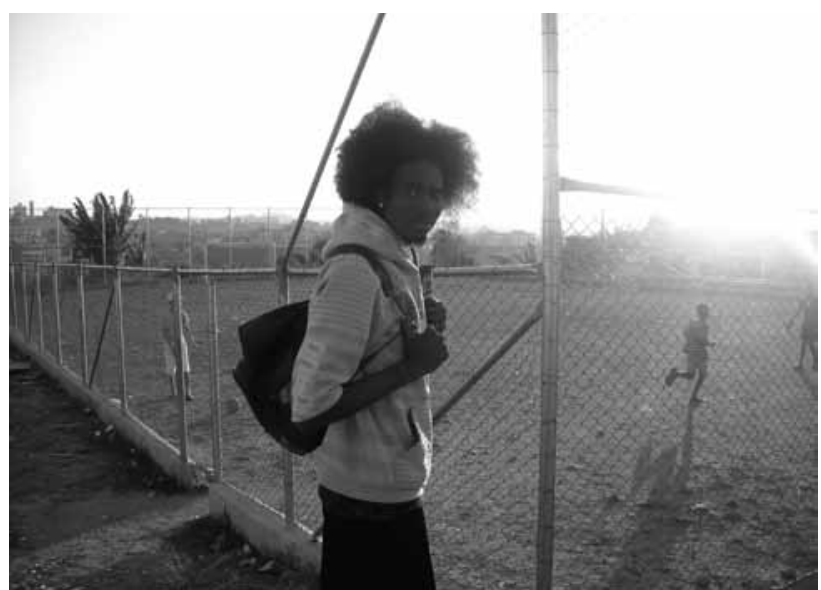

Daniel Hylário, protagonista do filme A arte e a rua.

Foto: Rosana Shimura

\section{IMAGEM 2}

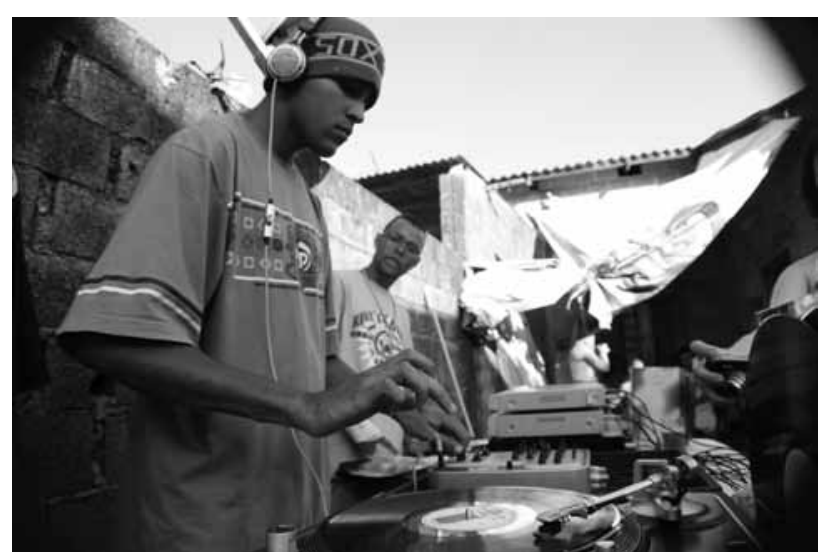

Divulgação do filme A arte e a rua.

Foto: Rosana Shimura
IMAGEM 3

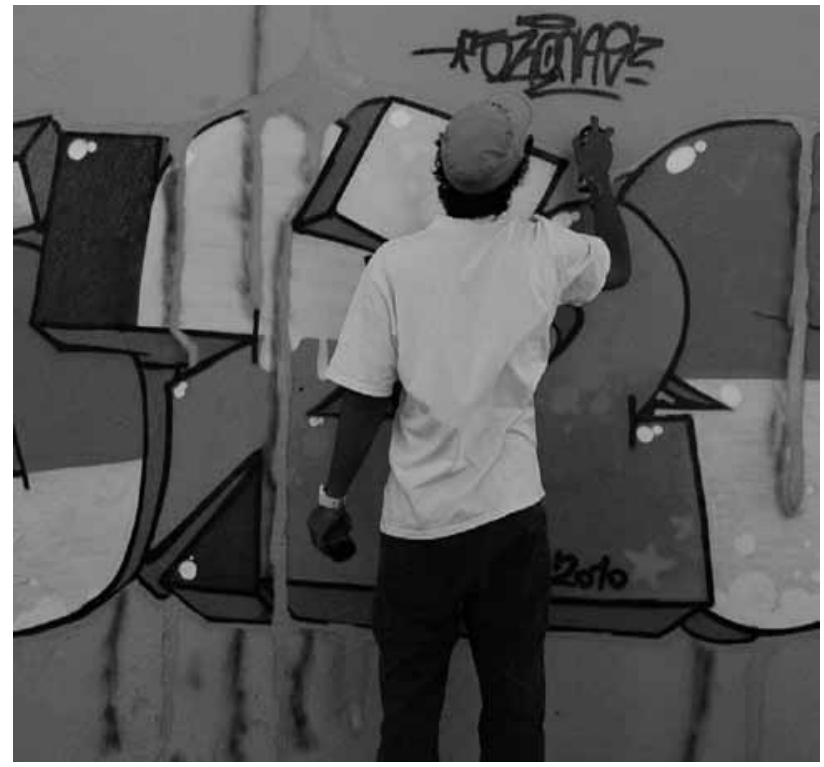

Cena de grafitagem do filme A arte e a rua.

Foto: divulgação 